\title{
Evaluating Land Use Quality in Coastal Area Using Fuzzy Logic
}

\author{
Lidija RUNKO LUTTENBERGER
}

\begin{abstract}
The purpose of the paper is to propose a model for evaluating land use quality and its variations to be used for planning the use of the space, issuing the permits and producing the environmental impact studies. Elaborated is the case of Quarner bay situated in northern part of the Adriatic Sea. Input parameters considered are variation in size of impervious surfaces, transforming the coastal belt into industrial zone, pressures from maritime transport, road transport, utilities sector, power generation sources and technology and the quality of governance prevailing at national and local level. Fuzzy inference system is used to calculate the output land use quality parameter integrating health, environment, quality of living of the local community and of tourism. Selected input parameters should be further developed and constantly monitored.
\end{abstract}

Keywords: coastal area; environmental modelling; fuzzy logic; indicators; land use quality

\section{INTRODUCTION}

There exist many methods for measuring the quality of the environment and the indicators for transmitting the perception thereof. Very often the parameters are measured for the sake of presenting national statistics or for measuring certain particular local phenomenon e.g. for determining the quality of bathing water, air quality near the polluting facility, etc. Both are absolutely useful considering reference territorial and application scope. However, should one wish to use such data to perceive quality of the environment in its integrity at a specific geographical area that shares common environmental problems, neither of the two approaches conduces to satisfactory solution, one being too general to be averaged, and the other one being too fragmented to be integrated and used for some other more general purpose. Those in the third category, aggregated indicators, are readymade, but always designated for some specific purpose.

Therefore the author attempted to design a method for determining the quality of the environment that is tailor-made and site-specific, particularly in the regions exposed to pronounced pressure of land development, as is the case in Croatia, a country extremely rich in natural beauties and the variety of its ecosystems, while on the other hand prone to transition vulnerabilities, especially with regard to regulating its land use in sensitive coastal karst area, one of the most complex existing ecosystems.

\section{INDICATORS, THEIR PRECISION AND RELEVANCE}

On the basis of global and regional experience, a system of sustainable development indicators for coastal zones and the sea must be introduced which will suit the capabilities and particular features of Croatia with respect to karst characteristics of its coast and the islands in which the process of pollution takes a course which differs from that in other parts of the region [1]. The areas having exceptional landscape value and the areas of tourist infrastructure development should be considered, in particular the interaction of various drivers with the resources of certain specific industries such as tourism for which the state of the environment is the prerequisite for its very operation.

As the complexity of a system increases, our ability to make precise and significant statements about its behaviour diminishes until a threshold is reached beyond which precision and significance (or relevance) become almost mutually exclusive characteristics. A corollary principle may be stated succinctly as, "the closer one looks at a real-world problem, the fuzzier becomes its solution". Therefore, as scientists used ever more detailed math and peered closer and closer at complex systems in engineering, economy, weather, forecasting, and biology, the father of fuzzy logic, Lotfi Zadeh [2], saw that as the system got more complex, precise statements had less meaning. He later called that the principle of incompatibility. Precision up, relevance down [3].

The use of fuzzy logic in environmental matters is not new, see [4-6]. The advantage of fuzzy logic-based model application in environmental applications is its tolerance to very often imprecise data and the fact that it is based on natural language. Furthermore, it can be built on top of the experience of experts meaning that knowledge can be added gradually and can implement holistic approach.

\section{SETTING}

For the purpose of presenting an example of application of the model, the author elaborated the case of the Rijeka bay that is the northmost part of Quarner situated in northern part of the Adriatic Sea, in Croatia, see Fig. 1.

Rijeka bay is located between western part of the Krk island coastline and Istrian peninsula and northern part of Croatian Littoral. Sea depth of the bay ensures safe navigation for Cape-size ships so major Croatian port developed there, along with significant tourist destinations. It is a submerged part of Dinaric karst. Dinaric karst is one of the two most valuable karst phenomena on the globe and the greatest continuous karst area in Europe. Karst landscape is an active laboratory of quite simple but endless chemical processes. Karst underground is holding 90 pct. of Croatian water resources, of which 99 pct. are in underground cracks. Variation between bottom and top level of underground waters in karst - ecotone - in Dinaric karst may fluctuate to 300 metres and constitutes the most valuable feature of underground habitats and are generators of species [7].

As stated in the Proposal of Physical plan of the County Littoral-Mountain [8] which is the administration unit of the area considered, the most pronounced conflicts in the narrow littoral area of the coastal part are those of petroleum processing, shipbuilding and ship repair industry, thermal power plant, transport (port, oil pipeline) on one part and housing, tourism and recreational activities on the other. 


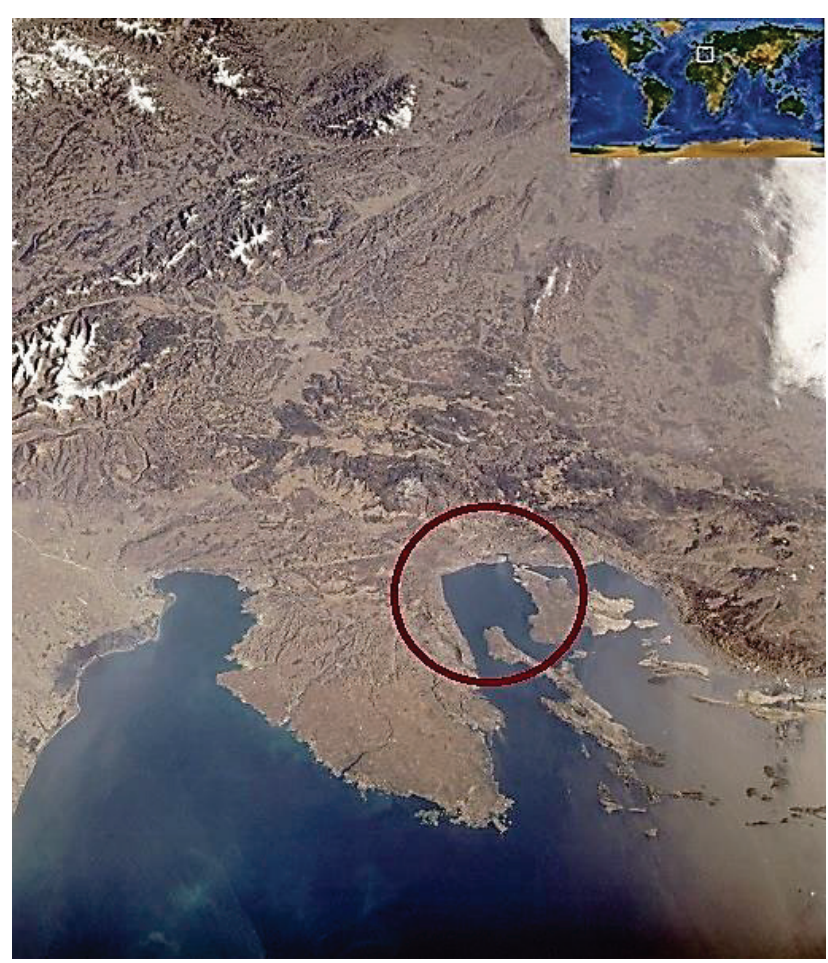

Figure 1 Rijeka bay, a part of Quarner bay considered (source NASA)

\section{MODEL BASED ON FUZZY LOGIC}

The author is proposing a model for evaluating land use quality and variations thereof, to be used for planning the use of the space, issuing the permits and producing the environmental impact studies. Land use quality can be largely attributed to population pressure on the land, a rapidly growing economy, poor land use planning, and the inconsistency in the governmental policies. Therefore, the following drivers are considered: variation in size of impervious surfaces, transforming the coastal belt into industrial zone, pressures from maritime transport, road transport, utilities sector, power generation sources in the area and technology and the quality of governance prevailing at national and local level. Those are the parameters that should in the author's opinion be considered in planning the use of land, issuing the permits and producing the environmental impact studies in the area of the Rijeka bay. Fuzzy Logic Toolbox is used to create and edit fuzzy inference system within the framework of MATLAB [9]. Mamdani-type fuzzy inference was used to calculate the output land use quality parameter integrating health, environment, quality of living of the local community and of tourism, demonstrating its sensitivity to variations of different input parameters. In this particular case the choice of Mamdani method was based on its advantage of being intuitive, having widespread acceptance and being well-suited for human input [10].

A fuzzy logic system consists of four parts: fuzzifier, rules, inference engine, and defuzzifier.

First of all, crisp sets of the drivers are converted to fuzzy sets using fuzzy linguistic variables, fuzzy linguistic terms and membership functions shown in Fig. 2. Seven linguistic input variables are the following:

1) Impervious surfaces - IMPERV

2) Shoreline industrialization - SHOREIND

3) Pollution from maritime transport - MARTRANP

4) Road transport - ROADTRAN
5) Pollution from municipal utilities - MUTILITIES

6) Power generation sources - PGS

7) Governance at local and national level - GOV.

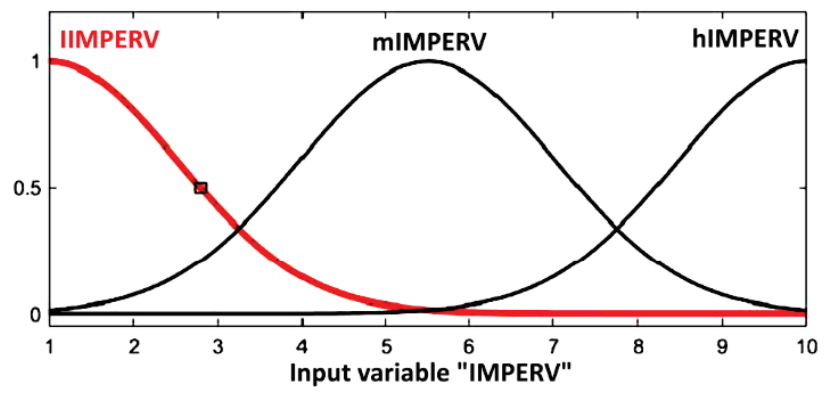

Figure 2 Membership functions for input variable IMPERV (low, medium, high), Gaussian type obtained using Matlab [9].

For the purpose of this study, crisp values of all input variables assume gradation from 1 to 10 . Tab. 1 provides the guidelines for valuation of selected variables. Its column 3 contains reference description of linguistic terms: 'high', 'environmentally unfriendly', 'non-renewable' and 'bad'. Column 4 pursues linguistic terms: 'low', 'environmentally friendly', 'renewable' and 'good'. Linguistic terms 'medium' and 'mixed' refer to the state where combination of elements from columns 3 and 4 apply. Owing to their significance, a task set for future work is definitely to devise the standard for valuing and measuring specified variables, not leaving it entirely to experts' judgements.

Fuzzy linguistic terms used are as follows: low-mediumhigh with regard to variables IMPERV, SHOREIND, MARTRANP, ROADTRAN, environmentally friendlymixed-environmentally unfriendly with regard to the variable MUTILITIES, renewable - mixed - non-renewable with regard to the variable PGS, and good-mixed-bad with regard to the variable GOV. It is precisely for the reason of difficulty in defining clear thresholds separating different values that fuzzy logic is applied.

The output linguistic variable is land use quality degradation - LUQD, which integrates health, environment, quality of living of the local community and of tourism. Gradation assumed is 1 to 10 here as well. Fuzzy linguistic terms with regard to the output variable are low-discerniblesignificant-high, see Fig. 3.

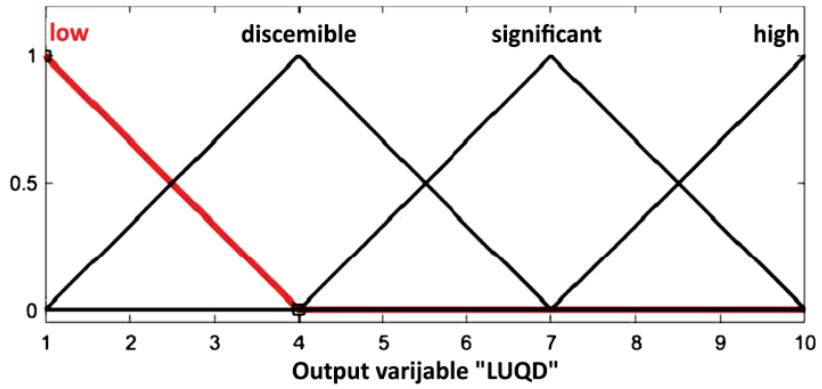

Figure 3 Membership functions for output variable LUQD, triangular-shaped obtained using Matlab [9].

The data concerning intensity of construction (impermeable surfaces) in local littoral can be readily obtained using satellite or air views [11]. Pollution originating from maritime transport should be provided by port authorities, while environmental degradation by road transport is correlated to the area and the length of paved 
roads, the number of cars, and the absence of low-emission road, rail and maritime public transport. The impact from municipal utilities can be measured from various discharges and technology used. Power (electricity and heat) generated in the area considered may be traced to renewable or nonrenewable sources and thus recorded, although one should also consider the impact of the power consumed locally, but generated elsewhere. Governance is the only variable that may not be measured in physical terms, but should be assigned a grade that is sufficiently objective and based on expert knowledge.

\section{Table 1 Guidelines for gradation of input parameters}

\begin{tabular}{|c|c|c|c|}
\hline 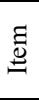 & Input variable & $\begin{array}{l}\text { Valuation: } \\
\text { high (items 1-4), environmentally unfriendly (item 5), non- } \\
\text { renewable (item 6), bad (item 7) }\end{array}$ & $\begin{array}{c}\text { Valuation: } \\
\text { low (items 1-4), environmentally friendly (item 5), } \\
\text { renewable (item 6), good (item 7) }\end{array}$ \\
\hline 1 & 2 & 3 & 4 \\
\hline 1 & $\begin{array}{l}\text { IMPERV } \\
\text { Impervious surfaces } \\
\text { (roads, driveways, } \\
\text { parking lots, roof } \\
\text { tops, sidewalks) }\end{array}$ & $\begin{array}{l}\text { - } \\
\text { - } \\
\text { Additional transportation of nonpoint source pollutants } \\
\text { affecting water quality } \\
\text { - } \quad \text { Decrease in groundwater recharge } \\
\text { - } \quad \text { Increase of stormflow and flood } \\
\text { - } \quad \text { Deforestation }\end{array}$ & $\begin{array}{l}\text { - } \text { Preserving the ecosystems } \\
\text { - LID - low impact development } \\
\text { - Permeable pavements } \\
\text { - Grass swales alongside roadways } \\
\text { - Green roofs } \\
\text { - Cisterns } \\
\text { - Infill }\end{array}$ \\
\hline 2 & $\begin{array}{l}\text { SHOREIND } \\
\text { Shoreline } \\
\text { industrialization }\end{array}$ & $\begin{array}{l}\text { - Air, sea, soil pollution } \\
\text { - Impaired public health in coastal communities } \\
\text { - Destruction of primary resource for tourism - landscape, } \\
\text { beaches }\end{array}$ & 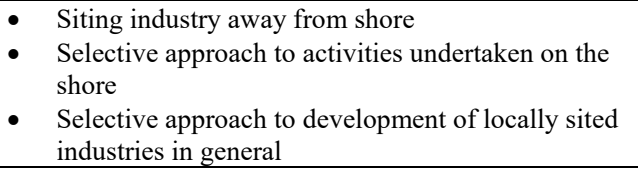 \\
\hline 3 & $\begin{array}{l}\text { MARTRANP } \\
\text { Pollution from } \\
\text { maritime transport }\end{array}$ & $\begin{array}{ll}\text { - } & \text { Air, sea pollution } \\
\text { - } & \text { Impaired public health in coastal communities }\end{array}$ & $\begin{array}{l}\text { - Using cleaner fuel, controlling the disposal of waste } \\
\text { and harmful substances from ships, ballast water } \\
\text { treatment }\end{array}$ \\
\hline 4 & $\begin{array}{l}\text { ROADTRAN } \\
\text { Road transport }\end{array}$ & $\begin{array}{l}\text { - } \quad \text { Low energy efficiency } \\
\text { - } \quad \text { Prevailing use of oil } \\
\text { - } \quad \text { Infrastructure taking up unspoiled land } \\
\text { - } \quad \text { Congestion pollution problems } \\
\text { - } \quad \text { Splitting communities and ecosystems } \\
\text { - } \quad \text { Air, water, soil pollution } \\
\end{array}$ & $\begin{array}{l}\text { - } \text { Orientation on railway transport } \\
\text { - } \quad \text { Short sea shipping powered by renewable sources } \\
\text { - } \quad \text { Public transport } \\
\text { - } \quad \text { Pedestrian infrastructure } \\
\text { - } \quad \text { Less urban sprawl - physical planning }\end{array}$ \\
\hline 5 & $\begin{array}{l}\text { MUTILITIES } \\
\text { Pollution from } \\
\text { municipal utilities }\end{array}$ & $\begin{array}{l}\text { - } \text { Great quantities of solid waste, wastewater } \\
\text { - } \quad \text { Potable water used for waste transport } \\
\text { - } \quad \text { Eutrophication } \\
\text { - }\end{array}$ & $\begin{array}{ll}\text { - } & \text { Recycling, reuse } \\
\text { - } & \text { Minimizing landfilled waste } \\
\text { - } & \text { Biogas production and composting } \\
\text { - } & \text { Stormwater collection } \\
\text { - } & \text { Decentralized wastewater systems } \\
\text { - } & \text { Proximity principle } \\
\end{array}$ \\
\hline 6 & $\begin{array}{l}\text { PGS } \\
\text { Power generation } \\
\text { sources }\end{array}$ & $\begin{array}{ll}\text { - } & \text { Using non-renewable sources and obsolete technologies } \\
\text { - } & \text { Centralized systems } \\
\text { - } & \text { Supply side management }\end{array}$ & $\begin{array}{ll}\text { - } & \text { Renewable sources } \\
\text { - } & \text { Decentralized systems } \\
\text { - } & \text { Energy efficiency measures } \\
\text { - } & \text { Smart grids } \\
\end{array}$ \\
\hline 7 & $\begin{array}{l}\text { GOV } \\
\text { Governance at local } \\
\text { and national level }\end{array}$ & $\begin{array}{ll}\text { - } & \text { Poor development strategy } \\
\text { - } & \text { Insufficiently regulated privatization } \\
\text { - } & \text { Speculative projects } \\
\text { - } & \text { Dominance of informal profit-oriented interest groups } \\
\text { - } & \text { Corruption } \\
\end{array}$ & $\begin{array}{l}\text { - } \begin{array}{l}\text { Preserving valuable resources, the environment and } \\
\text { quality of life }\end{array} \\
\text { - } \quad \text { Stimulating minor investments which internalize the } \\
\text { externalities } \\
\text { - } \quad \text { Attributing adequate value to public interest }\end{array}$ \\
\hline
\end{tabular}

Note: there are cross-effects, e.g. road construction creates impervious surfaces, as do big solar and wind power plants.

Fuzzy rule is a simple IF-THEN rule with a condition and a conclusion. The following five fuzzy rules define behaviour of the system:

\section{IF IMPERV is low} and SHOREIND is low and MARTRANP is low and ROADTRAN is low and MUTILITIES is environmentally friendly and PGS is renewable and GOV is good

THEN LUQD is low

2. IF IMPERV is high and SHOREIND is high and MARTRANP is high and ROADTRAN is high and MUTILITIES is environmentally unfriendly and PGS is non-renewable and GOV is bad

THEN LUQD is high

3. IF IMPERV is high

or SHOREIND is high

or MUTILITIES is environmentally unfriendly

or PGS is non-renewable

or GOV is bad

THEN LUQD is high

4. IF IMPERV is medium and SHOREIND is medium and MARTRANP is medium and ROADTRAN is medium and MUTILITIES is mixed and PGS is mixed and GOV is mixed

THEN LUQD is significant 
5. IF IMPERV is high

and SHOREIND is high

and GOV is high

THEN LUQD is high

Weight attributed to rules 1,3 and 5 is 1.0 and that attributed to rules 2 and 4 is 0.7 .

The author adhered to the principle of specifying the minimum number of rules necessary to define the system adequately. Therefore the postulate of the initial and basic rule No. 1 is that should all of the seven variables be of low value (intensity) simultaneously, the degradation of land use quality is low. It is implied herein that impaired land use quality is incurred as soon as a man intervenes in certain location or its surroundings. Rule No. 2 on the other hand states that if all variables hold high value simultaneously, then land use quality degradation is high. Rule No. 3 further elaborates behaviour of the system in a way that if any of the selected five variables IMPER, SHOREIND, MUTILITIES, PGS, GOV, considered to be particularly significant, is pronounced, then land use quality impairment is high. Fuzzy set operator OR in fact merges several simple fuzzy rules, in this case five, thus reducing the total number of rules. Rule No. 4 on the other hand states that if each of the used seven variables holds medium value, then land use quality is significant, meaning more than discernible, but not high. The last rule No. 5 states that even if three selected variables: IMPER, SHOREIND or GOV are pronounced simultaneously, in that case as well the land use quality degradation is significant. Rule No. 5 in fact elaborates further the criteria with regard to basic rule No. 1 .
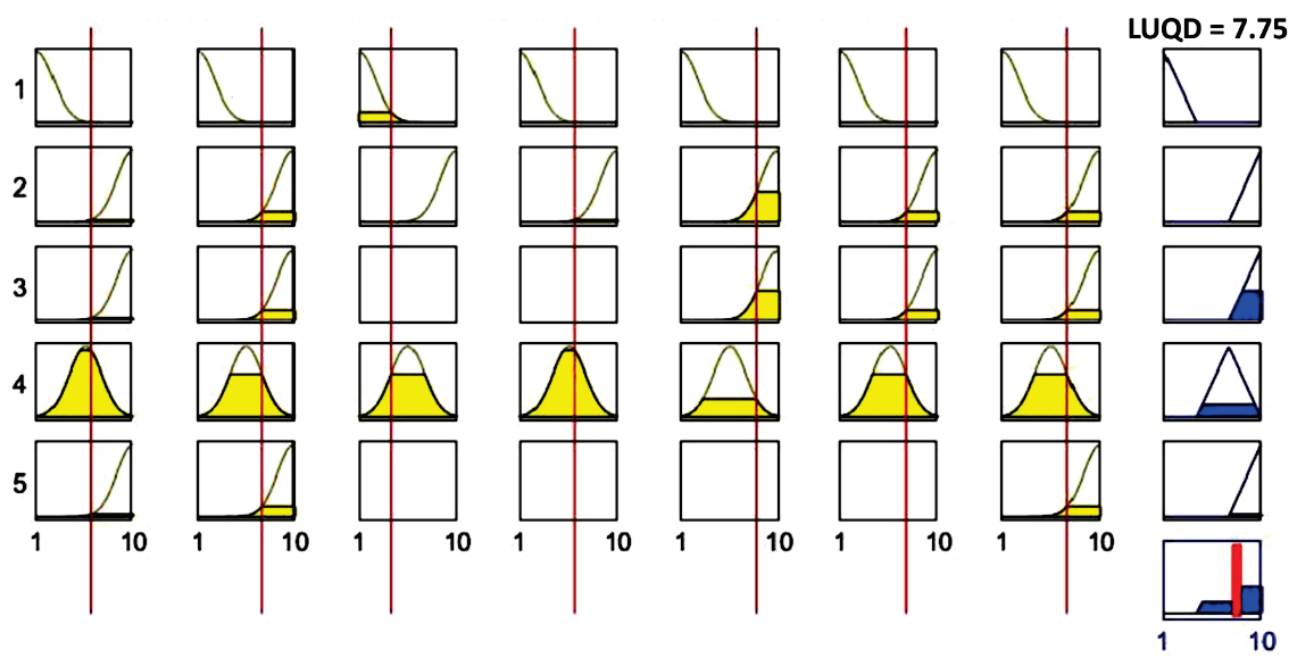

Figure 4 Rule viewer showing defuzzified aggregate output value of 7.75 in bottom right plot for [ 6746877 ] input values obtained using Matlab [9]

So the real power of fuzzy logic lies in the ability to reason using a small number of rules. Most rules are in this case concentrated on defining higher degree of environmental degradation. It is obviously possible to use greater or smaller number of rules, as well as different rules, depending on expert evaluation.

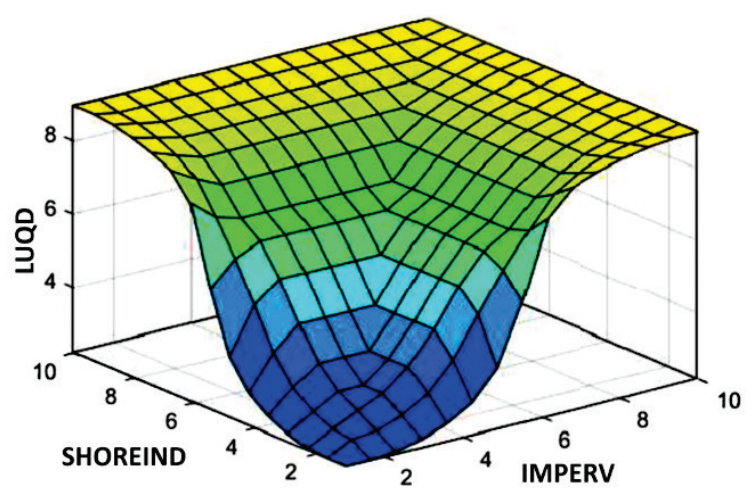

Figure 5 Output surface for input variables IMPERV and SHOREIND obtained using Matlab [9].

After the inference process in which the results of each rule are combined to obtain final result which is a fuzzy value, the result is defuzzified by centroid method to obtain a final crisp output. Rule viewer, Fig. 4, provides and interprets the entire fuzzy inference process.
MATLAB three-dimensional plot may show the output surface versus any two inputs to the system. Fig. 5 presents the output surface for input variables IMPERV and SHOREIND with all other input variables having the value of 2 .

One of the tasks for future research should be monitoring the behaviour of the system with regard to diversely set rules.

\section{CONCLUSION}

This example is to present possible model for obtaining the land use quality indicator based on input factors considered most appropriate and relevant. The model is flexible since different input parameters and fuzzy rules may be used in the context of different site-specific features. Selected input parameters should be further developed and constantly monitored.

The data obtained by fuzzy logic-based model agree with experimental knowledge or better to say actual status of the environment. Its advantage compared to other methods is the fact that it can integrate various aspects affecting the environment thereby ensuring holistic approach thereto.

It is of utmost importance not only to devise the standard of measurement for input variables used in this case study on account of their very significance, but also to monitor their change in time so as to obtain a historical record and to be as 
objective as possible in selecting and applying the rules which define behaviour of the system.

The method could as well be used in quantifying environmental impact studies, especially where several alternatives are considered.

\section{REFERENCES}

[1] Runko Luttenberger, L. (2007). Enhancing the Indicators of Sustainable Development of the Coastal Zone. Sustainable Development of Energy, Water and Environment Systems, Afgan, Naim H. (ed.), World Scientific Publishing Co., Singapore, 45-54. https://doi.org/10.1142/9789812771285_0005

[2] Zadeh, L. A. (1965). Fuzzy Sets. Information and Control, 8, 338-353. https://doi.org/10.1016/S0019-9958(65)90241-X

[3] Kosko, B. (1993). Fuzzy Thinking - The New Science of Fuzzy Logic, Hyperion, New York.

[4] Shepard, R. B. (2005). Quantifying Environmental Impact Assessments Using Fuzzy Logic, Springer. https://doi.org/10.1007/0-387-28098-7

[5] McKone, T. E. \& Deshpande, A. W. (2005). Can Fuzzy Logic Bring Complex Environmental Problems into Focus? Environmental Science \& Technology, 39(2), 42A-47A. https://doi.org/10.1021/es053163

[6] Aghajani, H. et al. (2011). Environmental Performance Evaluation Based on Fuzzy Logic. International Proceedings of Economics Development and Research (IPEDR), Vol. 5, IACSIT Press, Singapore, 432-436.

[7] Lučić, I., Karst, Major Croatian Dowry to the European Union, Croatian Radio Third Programme, 21.5.2012

[8] Proposal of Physical plan of the County Littoral-Mountain, Institute for Physical Planning of the County LittoralMountain, 4.3.2013.

[9] Mathlab 2018a, The Mathworks, Inc. Natick, USA, 2018

[10] Fuzzy Logic Toolbox User's Guide Version 2, The Mathworks, Inc., 1995-2001.

[11] Runko Luttenberger, L. \& Luttenberger, L. (2013). The use of GNSS data in environmental governance. $7^{\text {th }}$ Annual GNSS Vulnerabilities and Solutions Conference, Baška, Krk Island, 18-20 April.

\section{Contact information:}

\section{Lidija RUNKO LUTTENBERGER, PhD}

The School of Polytechnics, University of Rijeka,

Sveučilišna avenija 4, 51000 Rijeka, Croatia

E-mail: lidija.luttenberger@uniri.hr 